\title{
Finite Element Stress Analysis of Spiral Bevel Gear
}

\author{
Amlan Das ${ }^{\# 1}$ \\ \# Metallurgical and Material Engineering Department, \\ National Institute of Technology, Rourkela, Odisha, India \\ 1.amlandas08@gmail.com
}

\begin{abstract}
Gears can be classified as the category of moving machine parts which are responsible for the transmission of power over shorter distances i.e. from one shaft to another. These simple devices facilitate the modification of quantitative aspects of a power source like speed, torque and direction. Spiral bevel gears emboss in itself the structure of helical teeth which can be aligned with respect to others in an intersecting manner. Comparatively it gives the advantage of less vibration and noise.

This paper presents the analysis of a Spiral Bevel Gear in parametric mannerism with the objective of improving the transmission performance. Bending and surface strength of the gear tooth are the prime agents responsible for failure. Consequently, evaluation of stresses is a necessary methodology for minimizing failures and for obtaining an optimal design. Modelling of the gear has been carried out in the initial phase which includes revision of gear parameters like number of teeth, spiral angle, face width, bearing load. The next stage deals with analysis of the models with ANSYS 14.5 and subsequent determination of bending and contact stress values.

Analytical calculations are carried out with reference to AGMA gear equations. The results are further compared with FEM results. The obtained theoretical value shows good agreement with the FEA result. This leads to the conclusion that the proposed gear model is feasible.
\end{abstract}

Keyword-Spiral Angle, Face Width, Bending Stress, FEM

\section{Introduction}

Gear can be termed as a toothed wheel which is engaged with a similar toothed wheel with the objective of varying the speed or direction of transmitted motion. Mechanically, we can speak of it as a device which permits rotational force to be transferred to another gear or device. They come in all forms with their utility ranging from watches to heavy machine equipment. They can be produced by casting, forging, sintering from powdered metal. The spiral bevel gear geometry and terminology is depicted in Fig. 1(a) and (b). Smooth transmission and silent operation with the existence of large ratio and high speed are the essential features of spiral bevel gears. They have a continuous pitch line contact with larger number of teeth remaining in contact. A gradual engagement of teeth is observed rather than a sudden full line contact. The continuous pitch-line contact provides superior performance with a smaller number of pinion teeth as compared to straight bevels.

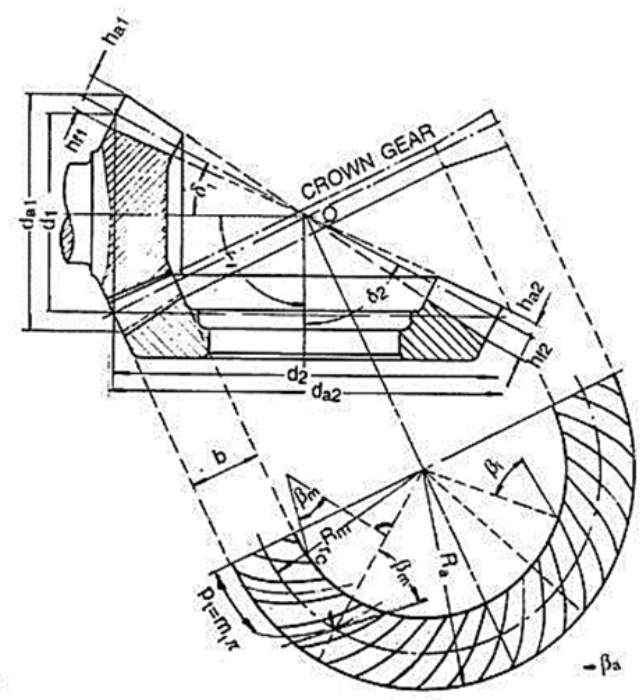

Fig. 1(a). Spiral Bevel Gear Geometry 


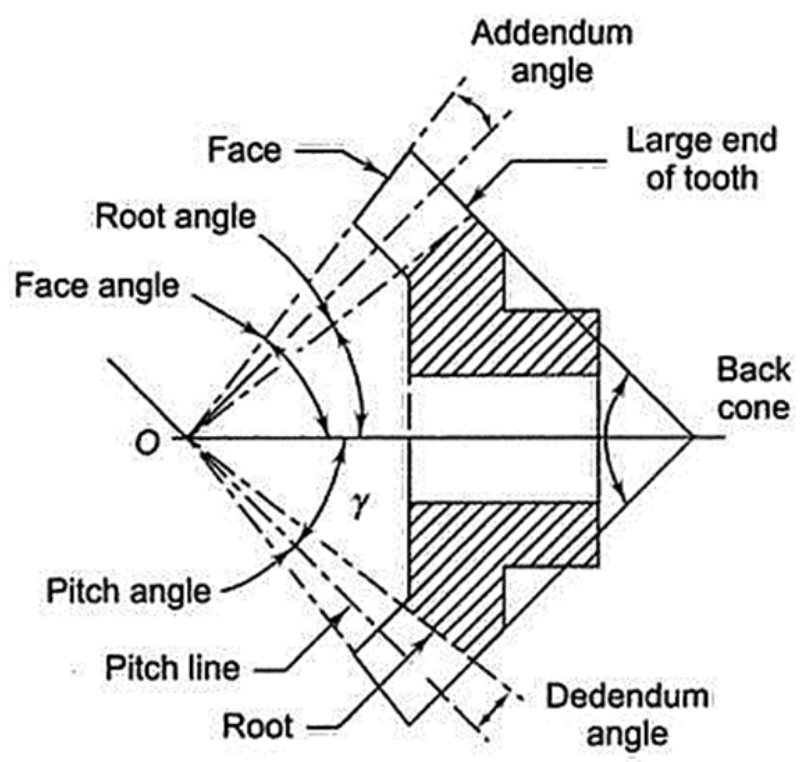

Fig. 1(b). Bevel Gear Terminology

Spiral bevel gears exert more thrust load on its bearings compared to other bevel gears. The directions of forces in a spiral bevel gear are shown in Fig. 2.
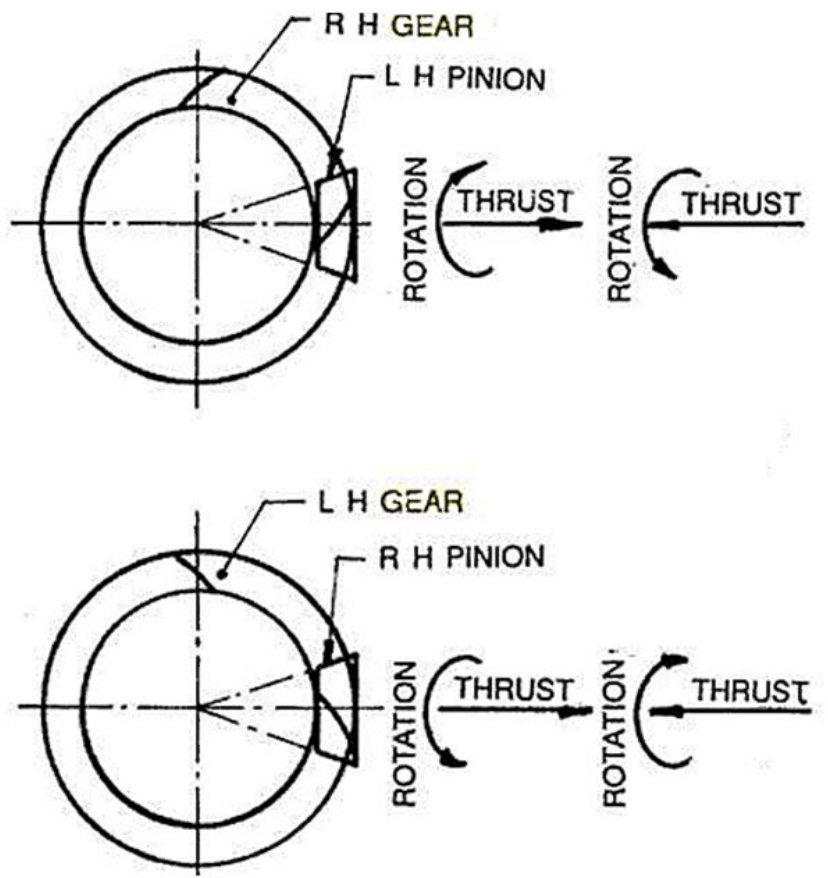

Fig. 2. Direction of thrust and rotational forces in a spiral bevel gear

The standards for design, analysis and manufacture of bevel gears are developed by American Gear Manufacturing Association (AGMA). The first step involves prediction and understanding the conditions under which the gear will operate. Load and speed parameters also form an important part of the design process. Additionally, we have to consider operating environment, lubrication, expected life etc.

Spiral bevel gears have complex tooth surface geometry due to which they require better technology and techniques. Analytical techniques like tooth contact analysis, loaded tooth contact analysis, under cut checking, stress analysis are used to calculate optimal tooth surface with permissible contact pattern position, smoothness of motion and assembly adjustment. 
Analytical methods employed for gear design and analysis included numerous assumptions which affected the accuracy. With the advent of CAD - CAM software, it is handy to go for detailed procedures. Numerical approach aids in the development of theoretical methodologies to predict the effects. Numerical methods are superior, precise and there is less constraint over assumptions. However, the imperative thing is to choose the correct model and the solution methods to get the perfect results and also reasonable computational time.

\section{Literature Review}

Konstantinov and Djamdjiev (1979) discussed about an advanced automated forging systems which eliminated issues related to automatic loading equipment. This ensured continuous operation of the integrated manufacturing system. The manufacturing system was based on direct numerical control (DNC) and dealt with chipless forming. The finished products were bevel gears and similar parts with ready-to-mount teeth.

Weck et al. (1980) utilized multiple-coordinate measuring technique in order to get precise manufacturing deviations on bevel gears. The techniques were helpful in preparing an elaborate analysis of bevel-gear tooth geometry. It was recorded that the obtained results have a great influence in regards to the settings of the bevelgear cutting machine, when we intend to obtain desired flank geometry.

Nalluveettil and Muthuveerappan (1993) carried out finite element analysis of a straight bevel gear tooth for evaluation of bending stresses wherein isoparametric brick element was selected for FEA. Stress distribution results at the root of the tooth were compared with the experimental results. The tooth behaviour at the root was studied by altering different parameters like pressure angle, rim thickness etc.

Lim et al. (1993) presented a transient elastohydrodynamic lubrication (EHL) study on spiral bevel gears. Based on the consideration that there is effect of the rate of change of contact parameters, the time dependent Reynolds equation is solved and the fundamental characteristics of the dynamic loading are investigated in detail and are compared with the Grubin's approximations.

Vijayarangan and Ganesan (1994) investigated the results of static load distribution analysed by 3D finite element method on a composite bevel gears. Comparative studies on the performance of composite gear showed that the static strength of glass epoxy bevel gear was nearly closer to that of carbon steel bevel gear than that of boron/epoxy bevel gear. The displacement of glass/epoxy showed more deviation as compared to carbon steel which was even more for the boron/epoxy case. It was concluded that boron/epoxy is better than steel.

Vaidyanathan et al. (1994) utilized Rayleigh-Ritz method to calculate the flexural behaviour of a cantilevered annular sector plate of variable rigidity, which comprises of the effects of shear deformation and root stresses in a straight bevel gear. Numerical results are compared and found in good agreement with the FEA results.

Rao and Shunmugam investigated tooth surface geometry of spiral bevel gears through a mathematical model which encompassed the theory of conjugate surfaces and principles of differential geometry. It also includes a computational and theoretical comparative study in regards to involute spiraloid surface with actual surface.

Zhang et al. (1995) suggested an innovative design approach wherein spiral bevel gears can be face milled with modified tooth surface geometry which will result in reduced noise levels and better stability. Local synthesis of gear was done and the meshing and contact of the gear drive is shaped by computational means. Synthesis approach defines the use of a predesigned parabolic function which separates out unwanted transmission errors initiated by misalignment and also considers the direct relations between principal curvatures and directions for mating surfaces.

Lin and Tsay (1997) proposed a mathematical model which followed the concept of grinding mechanism and machine-tool settings of the Gleason modified roll hypoid grinder. It was observed that entire machine-tool settings and machine constants included in the mathematical model displayed outstanding similar results in comparison with actual manufacturing machines.

Shunmugam et al. (1998) present a method for deterring the normal deviation bevel gears. With this method exact spherical involute is outlined and straight tooth and spiral tooth bevel gears are used for validation. Effectiveness of the suggested idea for finding normal deviation is introduced by conceptualizing spiral bevel gear geometry centred on circular arc.

Suh et al. (2002) suggested an indirect measurement technique built on virtual gears model (VGM), which is derived by NUBS fitting of the surface points of CMM measurements. In spiral gear, precise direct measurement with the physical part is not viable due to presence of complexity. Comparison of CAD and VGM models leads to the automatic detection of various errors, for example tooth profile, tooth trace errors. The main attribute of this model is robust and does not required any special device. This model is further incorporated in the CAM-CNC and tested, the obtained results shows good agreement with the experiment and gets validated.

$\mathrm{Li}$ and $\mathrm{Hu}$ (2003) attempted to analyse a spiral bevel-geared rotor-bearing system in a dynamic manner. Spiral bevel gear pairs constraint equations are described briefly which has relation between general displacements. The dynamic behaviour and the vibration characteristics of the system are investigated with other 
parameters, for instance critical speeds in journal supports, stability threshold speed and unbalanced responses in hydrodynamic journal bearings.

Wang and Fong (2005) found out methods to define the machine settings with modified radial motion (MRM) correction at specified contact point with programmed motion curve and contact path bias on pinion tooth surface. Parameters of MRM correction are evaluated according to the equations of meshing and correlation between mating curvatures at specified contact point. In order to verify the proposed method numerical examples are stated con revealed that, the bias of contact pattern and the motion curve were powered separately.

Litvin et al. (2006) implemented local synthesis algorithm for design, manufacturing, stress analysis of spiral bevel gears. Their experimental results were aimed at reducing noise levels, less vibration and improved durability.The optimized spiral bevel gear was presented by improving the bearing contact and providing parabolic function of transmission errors that resulted in increasing the endurance limit of the gear drives.

Tsai and Hsu (2008) used a cup-shape grinder or milling cutter for manufacturing the spiral bevel gear sets. In their previous publications, they discussed about a general meshing constraint equation for designing and constructing solid model whereas in present work they have derived meshing constraint equation of bevel gear sets having point-contact characteristics. They conclude it to be a novel approach for manufacturing spiral bevel gears and the major attribute is that the spiral bevel gears have single axis motion and which can be controlled during the cutting process.

Pio et al. (2013) delivered a novel method for kinematic and power flow analysis of bevel epicyclic gear train having gyroscopic complexity. A new formula was deduced and replaced spur gear trains with bevel gears and the Willis equation are further modified with new power ratio expressions and the equation was validated with bevel gears.

Bahrami et al. (2014) developed a model for straight bevel gear which could predict the film thickness and friction coefficient under the mixed-lubrication regime. Using Tred gold approximation each pair straight bevel gear teeth is substituted with a compound pair of spur gear teeth and the transmitted load and radii of curvature is evaluated. The effect of load, roughness, hardness, and rolling speed parameters are investigated in the gear system which helps in understand the concept of load sharing with consideration of elastic, elasto-plastic and plastic deformation for asperities.

\section{Mathematical Model}

The calculation of bevel gear-tooth-bending and surface fatigue strengths (Contact Stress) is quite complicated for Spiral Bevel gears. A brief description is provided here. One should refer to AGMA articles and publications by Gleason Machine Division for better inputs.

The equation for bevel gear-bending stress is similar to that of spur gears:

$$
\sigma_{b}=\frac{F_{t}}{b m J} k_{v} k_{o} k_{m}
$$

where, $\mathrm{F}_{\mathrm{t}}=$ Tangential load in $\mathrm{N}$

$\mathrm{m}=$ module at the large end of the tooth in $\mathrm{mm}$

$\mathrm{b}=$ Face width in $\mathrm{mm}$

$\mathrm{J}=$ Geometry form factor based on virtual number of teeth

$\mathrm{k}_{\mathrm{v}}=$ Velocity factor,

$\mathrm{k}_{\mathrm{o}}=$ Overload factor,

$\mathrm{k}_{\mathrm{m}}=$ Mounting factor, depending on whether gears are straddle mounted (between two bearings) or overhung (outboard of both bearings), and on the degree of mounting rigidity.

$$
\begin{aligned}
\sigma_{c} & =\sqrt{0.35 \frac{F_{t} E}{b d_{m}} \frac{u_{v}+1}{u_{v}} \frac{1}{\cos ^{2} \emptyset \tan \emptyset_{w}}} \\
u_{v} & =u^{2}=\frac{z_{2}}{z_{1}}
\end{aligned}
$$

Putting material coefficient,

$$
y_{m}=\sqrt{0.35 E}=\sqrt{0.35 \frac{2 E_{1} E_{2}}{E_{1}+E_{2}}}
$$

where, $E_{1}$ and $E_{2}$ are the moduli of elasticity of the pinion and the gear material and pitting the pitch point coefficient.

$$
y_{p}=\sqrt{\frac{1}{\cos ^{2} \emptyset \tan \emptyset_{w}}}
$$

On inserting the above terms, we get Contact Stress, 


$$
\sigma_{c}=y_{m} y_{p} \sqrt{\frac{F_{t}}{b d_{m}} \frac{\sqrt{u^{2}+1}}{u}}
$$

Since $\left[\phi_{n}=20^{\circ} \psi=35^{\circ}\right.$ and $\left.\Sigma=\gamma_{1}+\gamma_{2}=90^{\circ}\right]$

\section{Methodology}

The equation of motion of Spiral bevel gear is solved using FEA tool (ANSYS) as the equation of motion for a gear is difficult to visualize therefore some FEM tool is the solution method for analysing stress of gear with various aspect ratio.

ANSYS 14.5 finite element program was instrumental in stress analysis. To achieve this, key points were first formed and then line segments were shaped. The lines were joined to create an area. Finally, this area was extruded. The gear has been modelled different number of teeth. A 3-D structural based solid element was designated to model the gear. The gear was discretized into 35359 elements with 63404 nodes. The boundary conditions were specified by constraining all degrees of freedoms of the nodes located on the left end of the gear. For bending and contact stress analysis the spiral bevel and straight gear pair with the properties given in table 5.1 was chosen to model. To minimize computation time, meshed gear with one tooth is imported to ANSYS Workbench 14.5 for analysis.

Table 1. Spiral Bevel Gear parameters

\begin{tabular}{|c|l|c|}
\hline $\mathbf{1}$ & Modulus of Elasticity & $\mathbf{2 0 2}$ GPa \\
\hline $\mathbf{2}$ & Poisson ratio & $\mathbf{0 . 3}$ \\
\hline $\mathbf{3}$ & Type of Gear & $\begin{array}{c}\text { Standard Involute, } \\
\text { Full depth }\end{array}$ \\
\hline $\mathbf{4}$ & Module & $\mathbf{4 . 5} \mathbf{~ m m}$ \\
\hline $\mathbf{5}$ & Pressure Angle & $\mathbf{2 0}$ \\
\hline $\mathbf{6}$ & Spiral Angle & $\mathbf{3 5}$ \\
\hline $\mathbf{6}$ & Face width(F) & $\mathbf{4 0 ~} \mathbf{~ m m}$ \\
\hline $\mathbf{7}$ & No of teeth(N) & $\mathbf{9 , 3 6 - 4 5}$ \\
\hline $\mathbf{8}$ & Pitch Diameter & $\mathbf{1 6 2} \mathbf{~ m m}$ \\
\hline $\mathbf{9}$ & Transmitted load(W) & $\mathbf{3 0 0 0} \mathbf{~ N}$ \\
\hline $\mathbf{1 0}$ & Revolution Per Minute(RPM) & $\mathbf{3 0 0 0}$ \\
\hline $\mathbf{1 1}$ & Torque & $\mathbf{1 5 0} \mathbf{~ N m}$ \\
\hline $\mathbf{1 2}$ & Material & $\mathbf{S C M 4 2 0}$ \\
\hline
\end{tabular}

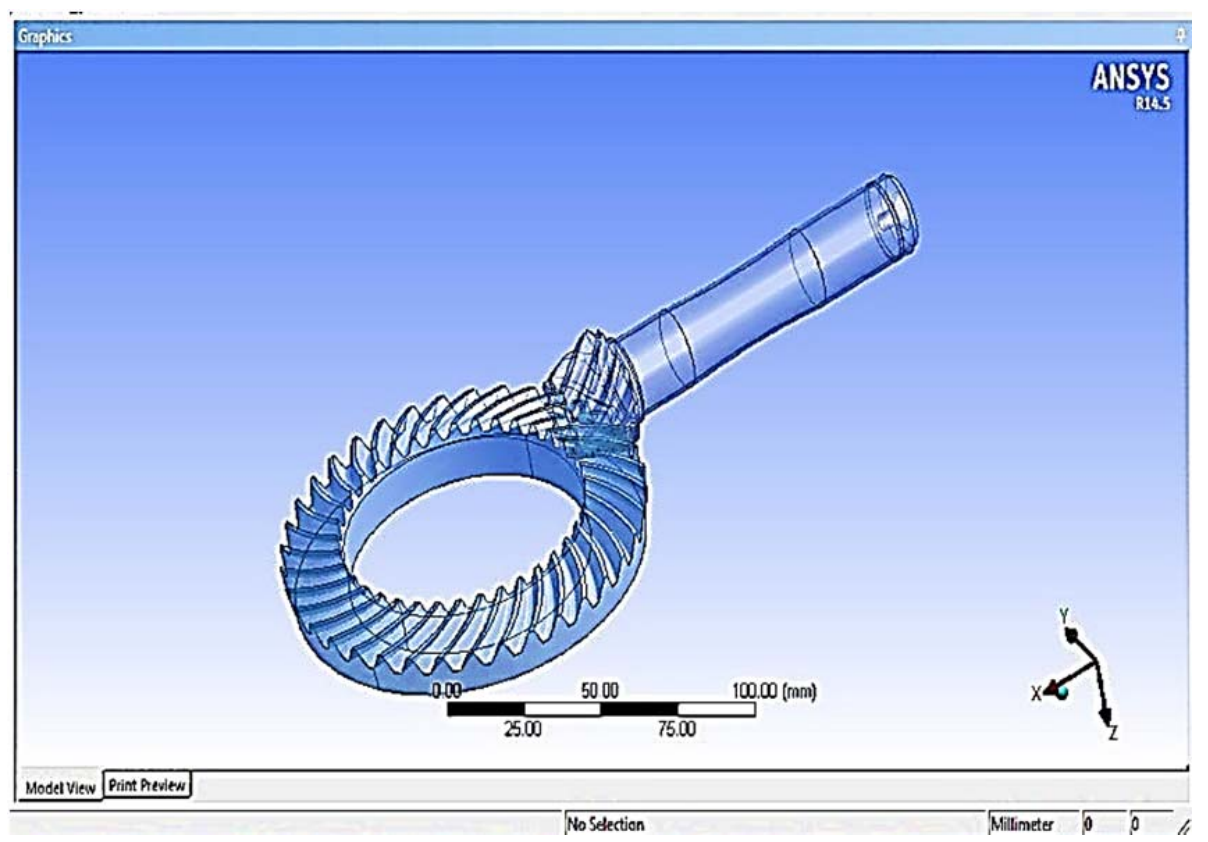

Fig. 3. Modelled Geometry 


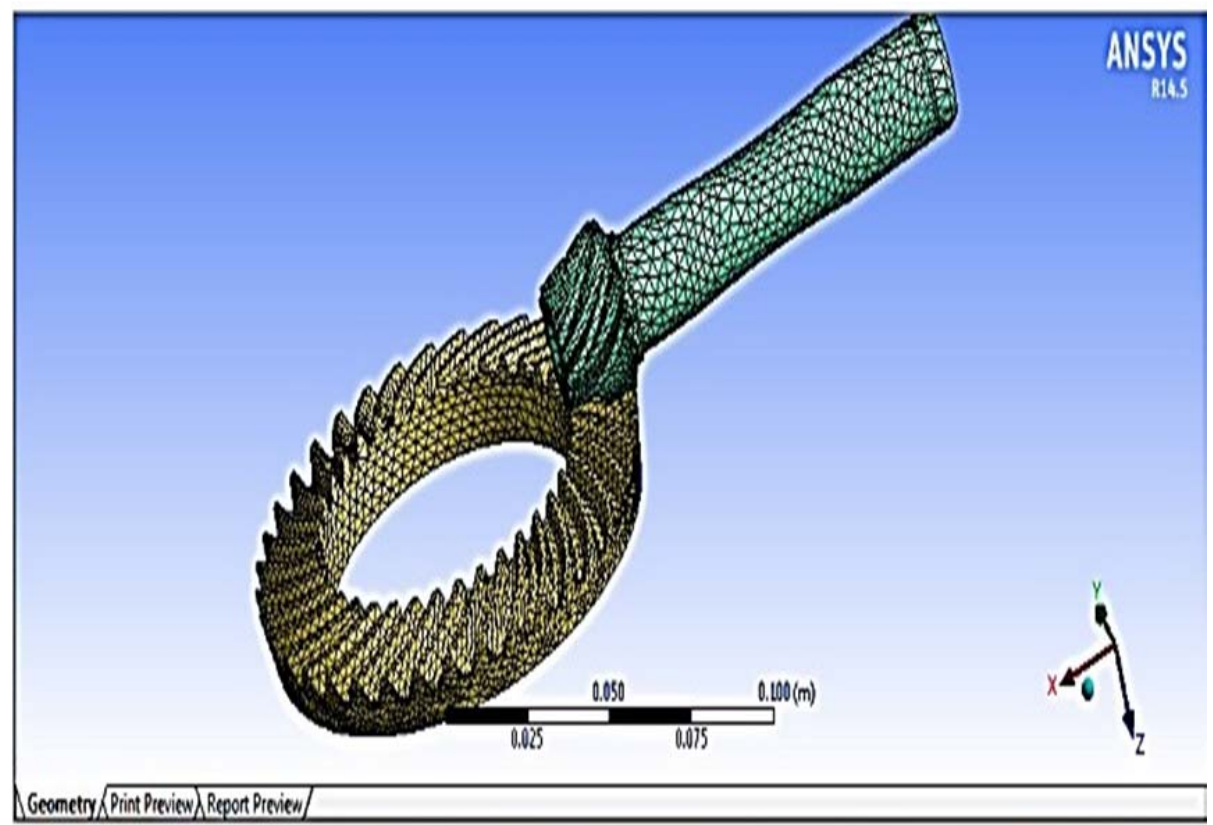

Fig. 4. Mesh Model

\section{Results and Discussion}

We have depicted the results for stress analysis of Spiral Bevel gear using ANSYS as well as through analytical methods. The parametric study of effect of face width, varying load, number of teeth on bevel gear is done. The FEM results are validated with literature based on Faydor [14].

Table 2. Validation of Von-Mises Stresses for spiral bevel gear models

\begin{tabular}{|l|l|l|l|}
\hline Stresses & & Gear & Pinion \\
\hline $\begin{array}{l}\text { Bending } \\
\text { Stress }\end{array}$ & FEM Reference [18] & 143 & 102 \\
\hline & FEM Present (ANSYS) & 144.1 & 103.1 \\
\hline & Faydor (Expt.) [14] & 167 & 110.3 \\
\hline & FEM Present (ANSYS) & 168.9 & 111.1 \\
\hline \multirow{2}{*}{$\begin{array}{l}\text { Contact } \\
\text { Stress }\end{array}$} & Faydor (Expt.) [14] & 377.4 & 29.410 \\
\hline & FEM Present (ANSYS) & 379.2 & 30.8 \\
\hline
\end{tabular}

Table 3: Von-Mises (Bending) Stresses for Bevel Gear Models

\begin{tabular}{|c|c|c|}
\hline No of teeth(N) & AGMA Stresses(MPA) & 3D Stresses (ANSYS)(MPA) \\
\hline $\mathbf{3 6}$ & 219.2988 & 220.57 \\
\hline $\mathbf{3 8}$ & 203.4563 & 203.21 \\
\hline $\mathbf{4 0}$ & 184.2228 & 184.28 \\
\hline $\mathbf{4 2}$ & 168.4495 & 168.86 \\
\hline $\mathbf{4 4}$ & 155.1232 & 154.94 \\
\hline
\end{tabular}

For the number of teeth $(Z)=36$,

$\sigma_{b}=\frac{F_{t}}{b m J} k_{v} k_{o} k_{m}=219.29 \mathrm{MPa}$

For number of teeth $(\mathrm{Z})=38$, 
$\sigma_{b}=\frac{F_{t}}{b m J} k_{v} k_{o} k_{m}=203.45 \mathrm{MPa}$

For number of teeth $(Z)=40$,

$\sigma_{b}=\frac{F_{t}}{b m J} k_{v} k_{o} k_{m}=184.22 \mathrm{MPa}$

For number of teeth $(Z)=42$,

$\sigma_{b}=\frac{F_{t}}{b m J} k_{v} k_{o} k_{m}=168.449 \mathrm{MPa}$

For number of teeth $(Z)=44$,

$\sigma_{b}=\frac{F_{t}}{b m J} k_{v} k_{o} k_{m}=155.123 \mathrm{MPa}$

The stress distribution in Spiral Bevel Gear 3-D models and comparative results for different 3-D models and the corresponding AGMA stress values and present FEM values are depicted. We find good agreement between analytical and computational results. It can also be concluded that on increasing number of teeth of Bevel gear Von-Mises (Bending) Stresses decreases.

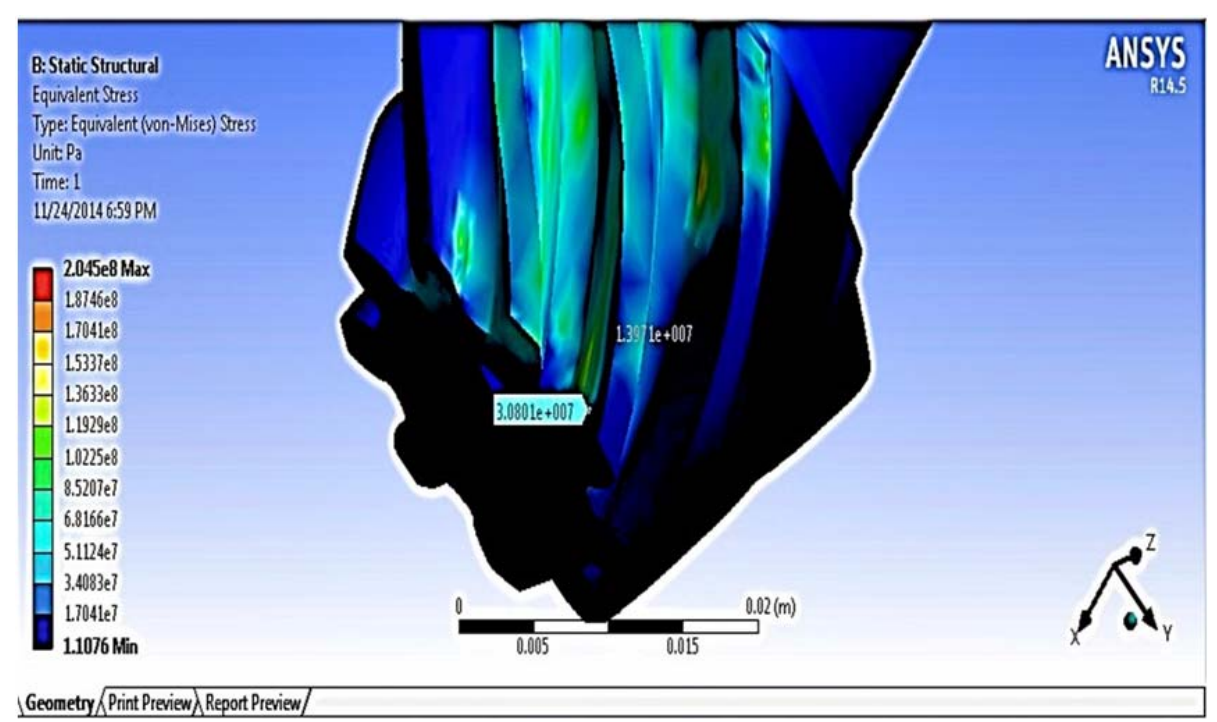

Fig. 5 Validation of Contact Stress for Spiral Bevel Pinion

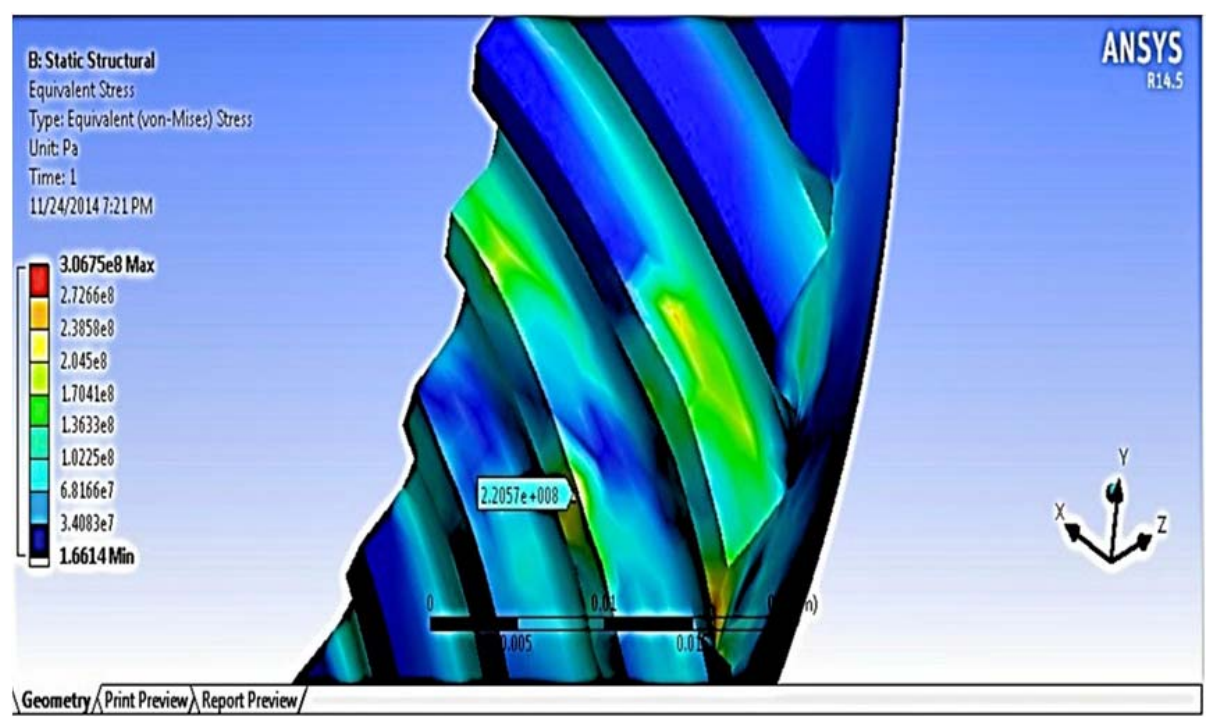

Fig. 63 -D Von-Mises Stress for Spiral Bevel Gear with 36 Teeth

Figure 6 - 10 depict the von-Mises stress for gears with different teeth. Validation of bending stress of spiral bevel gear of different configuration are done and compared with analytical results. It is found that the obtained result from FEA is near to the analytical one. It can be pointed out that the variation in FEA result is due to the element and node sizing. 
ISSN (Print) : 2319-8613

ISSN (Online) : 0975-4024

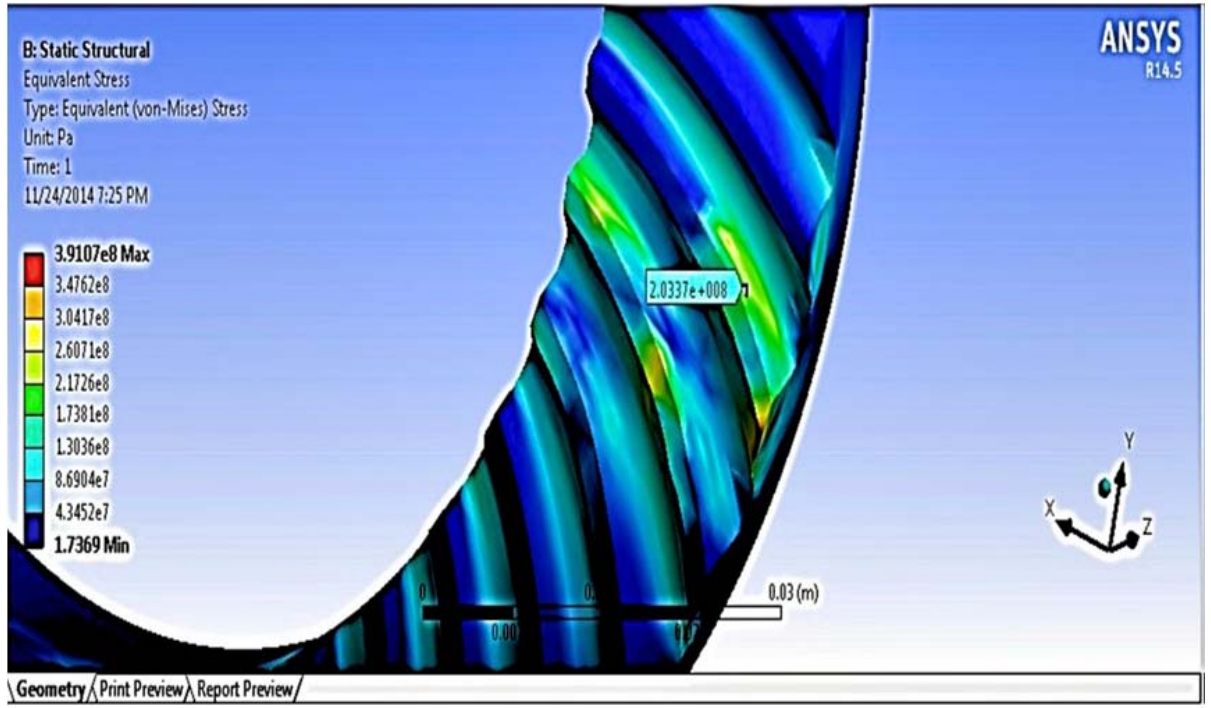

Fig. 7 3-D Von-Mises Stress for Spiral Bevel Gear with 38 Teeth

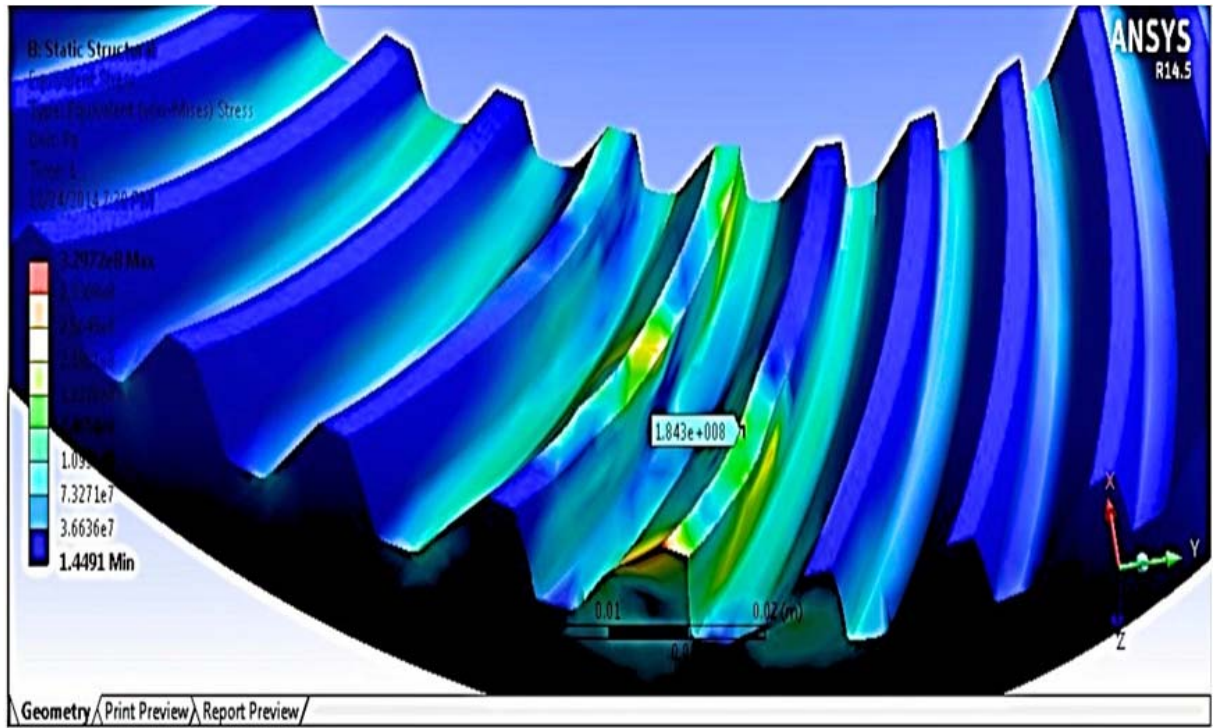

Fig. 8 3-D Von-Mises Stress for Spiral Bevel Gear with 40 Teeth

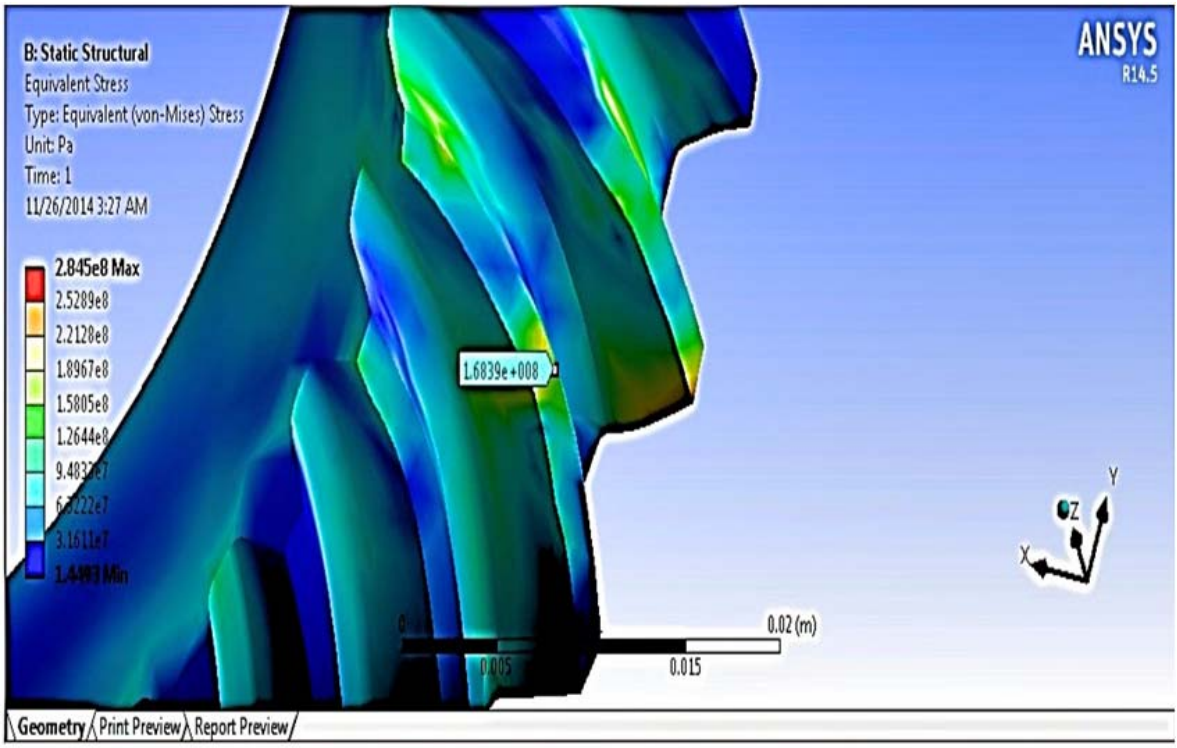

Fig. 9 3-D Von-Mises Stress for Spiral Bevel Gear with 42 Teeth 


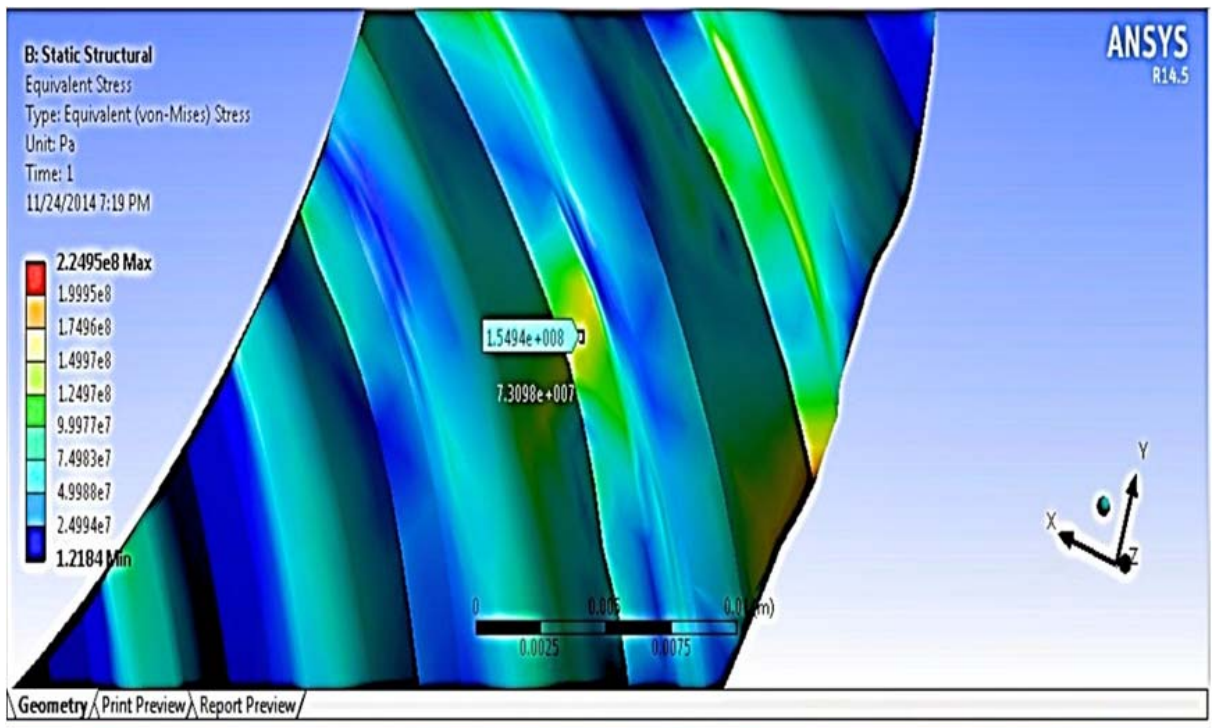

Fig. 10 3-D Von-Mises Stress for Spiral Bevel Gear with 44 Teeth

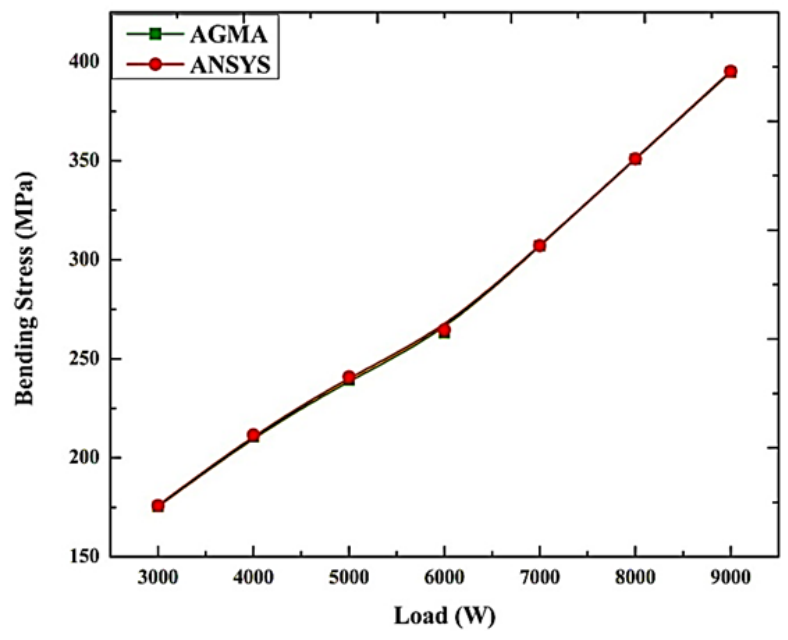

Fig. 11 Variation of Bending Stress with respect to Load

Fig. 11 shows the variation of bending stress with respect to load. It is seen that on increasing load (Ft) the bending stress of spiral bevel gear linearly increases. On increasing load, the bending stress increases from $16.63 \%-9.53 \%$ form initial. An interesting fact is noticed that this percent deviation significantly decreases as load increases.It can also be concluded the significance of load and bending stress played crucial role in material selection for gear design.

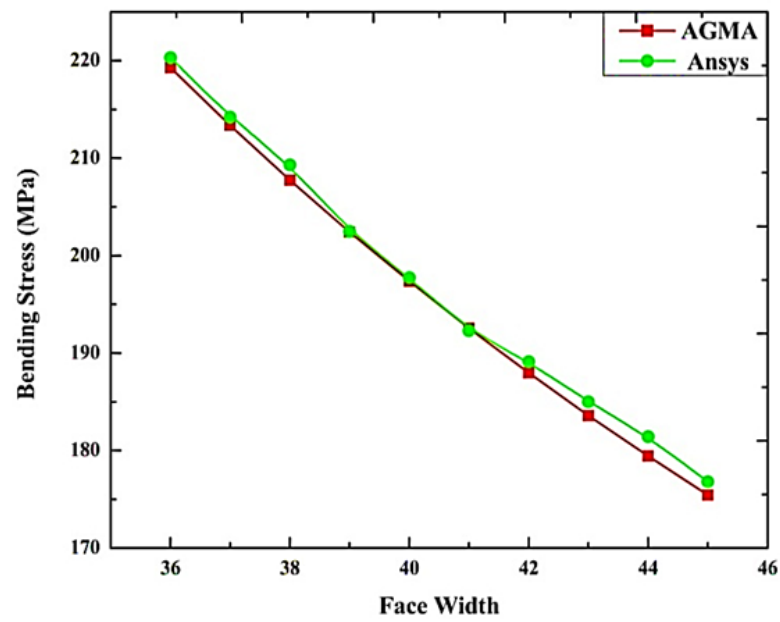

Fig. 12 Variation of Bending Stress with respect to Face Width 
Fig. 12 shows the Variation of Bending Stress with respect to Face width. From the figure it has seen that the bending stress linearly goes on decreasing as the gear face width increases. It can also be revealed that the decline trend even shows good and remarkable agreement with the FEA result.

Fig. 13 shows the Variation of Bending Stress with respect to Number of Teeth. It is evident that as the number of teeth increases of spiral bevel gear bending stress significantly goes on decreasing. And the FEA result very less deviation with the analytical (AGMA) result.

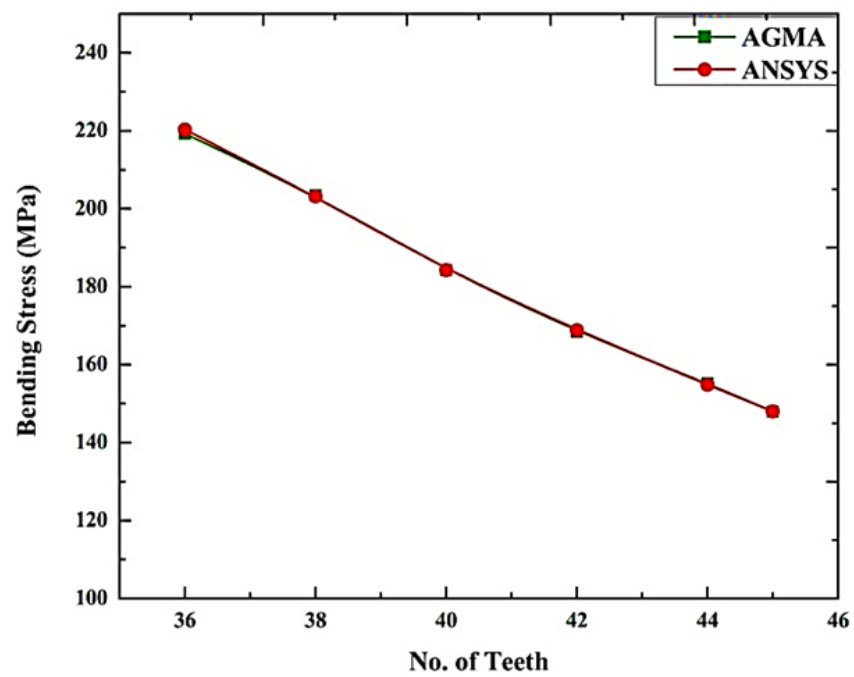

Fig. 13 Variation of Bending Stress with respect to Number of Teeth

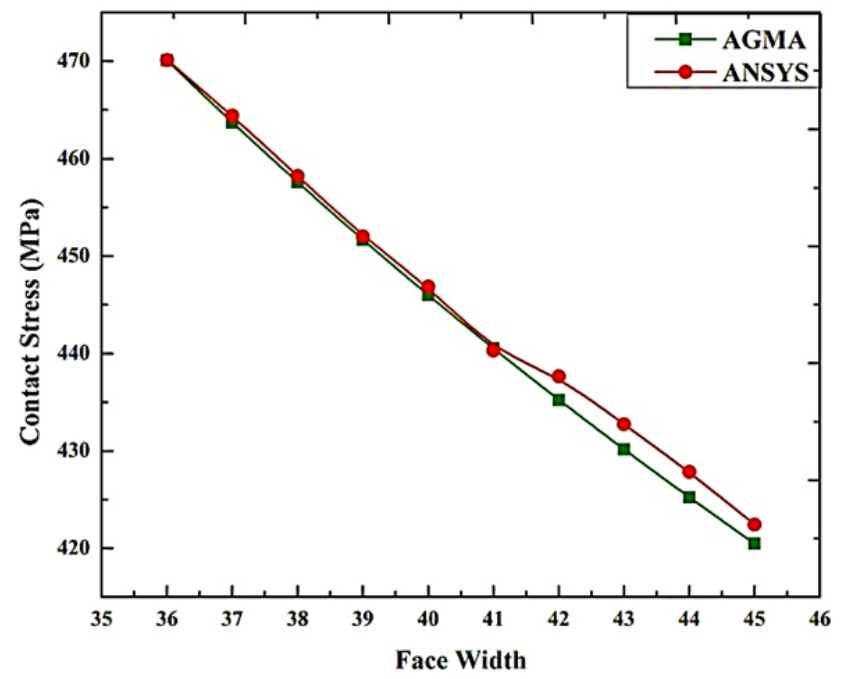

Fig. 14 Variation of Contact Stress with respect to Face Width

Fig. 14 shows the variation of Contact Stress with respect to Face width. From the figure it can be concluded that on increasing face width of spiral bevel gear linearly goes on decreasing. It has been also seen that the FEA (ANSYS) result also following the same trend and $0.61759 \%$ variation has seen from face width $42 \mathrm{~mm}$ to $45 \mathrm{~mm}$. 


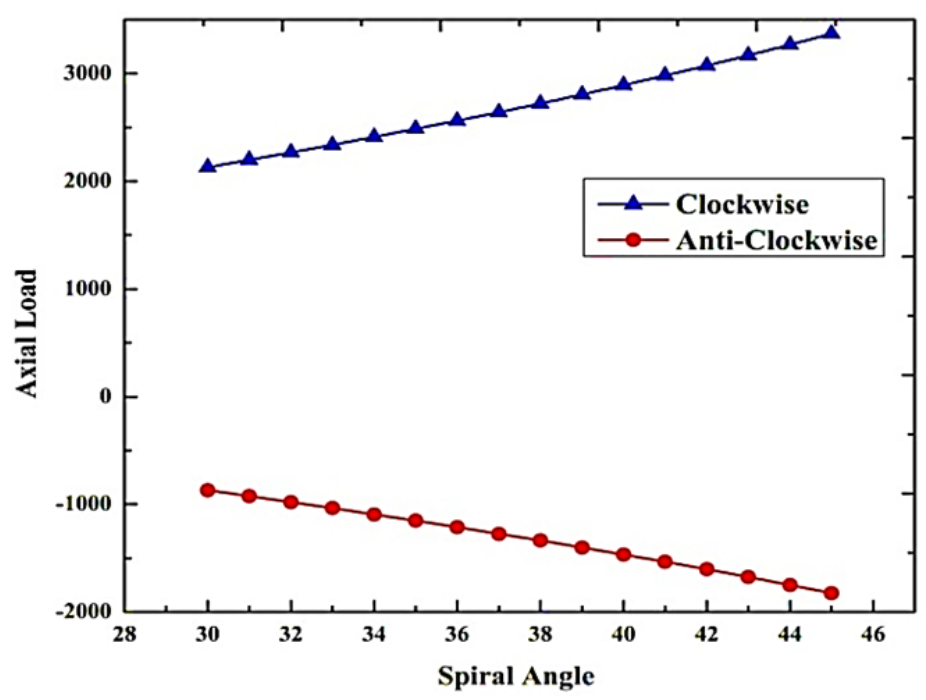

Fig. 15 Variation of Axial load with respect to spiral angle (Constant load)

Figure 15 and 16 shows the variation of axial load with respect to spiral angle for constant and varying load. It can be concluded that on increasing spiral angle the magnitude of axial load(Thrust) on clockwise direction and decrease in anti-clock wise direction since it depends upon the driver and driven member and also with hand of spiral.It can also be decided that on increasing tangential load (ft) with spiral angle the axial load acting of gear increase vigorously in clockwise direction.

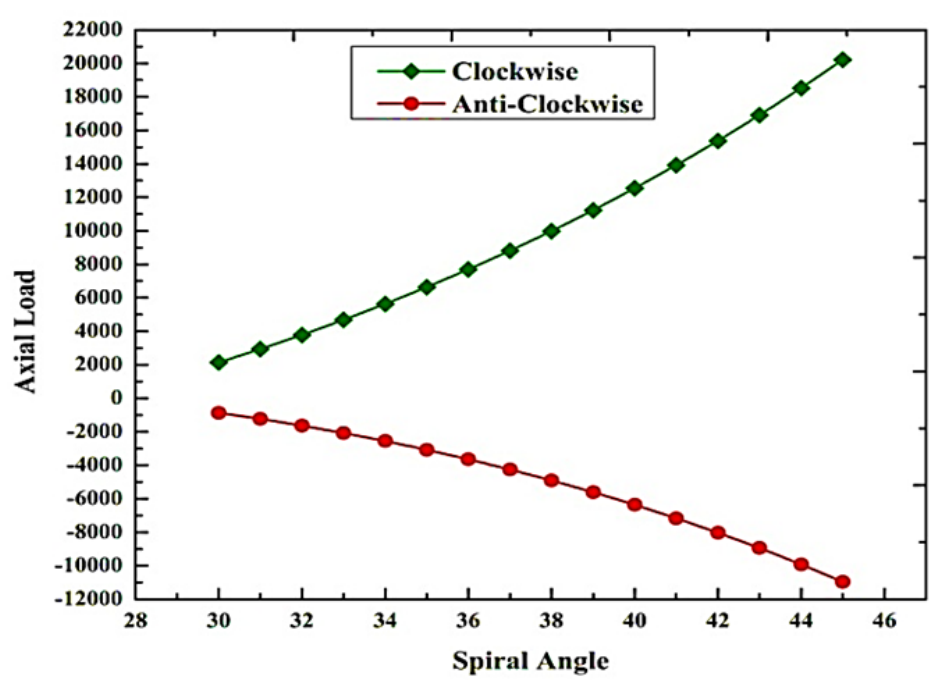

Fig. 16 Variation of Axial load with respect to spiral angle (varying load)

\section{Conclusion}

It was perceived that the stresses generated on Spiral bevel gear teeth alter with the number of teeth. It has been noted that on increasing face width, contact and bending stress decreases. Spiral angle also play a crucial role the axial force acting on bevel gear. The result comparison between FEM and AGMA (maximum bending stresses) and (maximum contact stresses) reveal that that the maximum stresses predicted by the FEM are slightly higher than those predicted by the AGMA.

It is important to state that the tooth height is an important gauge and it should be modified only if there are space limitations. A shorter gear tooth will yield more concentrated areas of stress which is preferably avoided. Hardness of a tooth profile can be amended to pitting failure i.e. a phenomenon in which small particles are removed the surface of the tooth. This is due to high contact stress occurred between teeth during mating.

In spiral bevel gears, spiral angle is main attribute in design consideration. Since spiral angle varies along with face width. Traditionally, a spiral angle $\beta$ varies from $30^{\circ}$ to $45^{\circ}$ and it is implemented in order to assure a smooth tooth action as well as it also influences gear ratio, tooth load and bearing load In Spiral bevel gears the pressure angle general made with $17.5^{\circ}$ and $20^{\circ}$. But most commonly $20 \mathrm{o}$ is preferred to design. The face width of spiral bevel gear is dependent upon the kind of application of the gearing and the cone distance at the back cone. 


\section{References}

[1] M.S. Konstantinov, N.V. Djamdjiev, “An integrated bevel gears manufacturing system”, Mechanism and Machine Theory, Volume 14, Issue 1, pp. $11-23,1979$.

[2] M. Weck, O. Guzman, P.W. Gold, "Measuring the flank geometry of bevel gears on a multiple-coordinate measuring machine", Precision Engineering, Volume 2, Issue 2, pp. 85-88, April 1980.

[3] S.J. Nalluveettil, G. Muthuveerappan, "Finite element modelling and analysis of a straight bevel gear tooth", Computers \& Structures, Volume 48, Issue 4, pp. 739 - 744, 17 August 1993.

[4] S.G. Lim, D.E. Brewe, R.F. Handschuh, "A Transient Elastohydrodynamic Lubrication Analysis for Spiral Bevel Gears",Tribology Series, Volume 25, pp. 157 - 168, 1993, Pages 157-16.

[5] S. Vijayarangan, N. Ganesan, "Static stress analysis of a composite bevel gear using a three-dimensional finite element method", Computers \& Structures, Volume 51, Issue 6, pp. 771-783, 1994.

[6] S. Vaidyanathan, H.R. Busby, D.R. Houser, "A numerical approach to the static analysis of an annular sector mindlin plate with applications to bevel gear design", Computers \& Structures, Volume 51, Issue 3, pp. 255-266, 3 March 1994.

[7] B. Subba Rao, M.S. Shunmugam, V. Jayaprakash, "Mathematical model for generation of spiral bevel gears",Journal of Materials Processing Technology, Volume 44, Issues 3-4, pp. 327-334, August 1994.

[8] Yi Zhang, F.L. Litvin, R.F. Handschuh, "Computerized design of low-noise face-milled spiral bevel gears", Mechanism and Machine Theory, Volume 30, Issue 8, pp. 1171-1178, November 1995.

[9] Chung-Yunn Lin, Chung-Biau Tsay, Zhang-Hua Fong, "Mathematical model of spiral bevel and hypoid gears manufactured by the modified roll method", Mechanism and Machine Theory, Volume 32, Issue 2, pp. 121-136, February 1997.

[10] M.S. Shunmugam, B.Subba Rao, V. Jayaprakash, "Establishing gear tooth surface geometry and normal deviationPart II-bevel gears",Mechanism and Machine Theory, Volume 33, Issue 5, pp. 525-534, 1 July 1998.

[11] S.H. Suh, E.S. Lee, H.C. Kim, J.H. Cho,"Geometric error measurement of spiral bevel gears using a virtual gear model for STEPNC",International Journal of Machine Tools and Manufacture, Volume 42, Issue 3, pp. 335-342, February 2002.

[12] M. Li, H.Y. Hu , "Dynamic Analysis ofa Spiral Bevel-Geared Rotor-Bearing System",Journal of Sound and Vibration, Volume 259, Issue 3, pp. 605-624, 16 January 2003.

[13] Pei-Yu Wang, Zhang-Hua Fong, "Mathematical model of face-milling spiral bevel gear with modified radial motion (MRM) correction", Mathematical and Computer Modelling, Volume 41, Issues 11-12, pp. 1307-1323, May 2005.

[14] Faydor L. Litvin, Alfonso Fuentes, Kenichi Hayasaka, "Design, manufacture, stress analysis, and experimental tests of low-noise high endurance spiral bevel gears", Mechanism and Machine Theory, Volume 41, Issue 1, pp. 83-118, January 2006.

[15] Ying-Chien Tsai, Wei-Yi Hsu, "The study on the design of spiral bevel gear sets with circular-arc contact paths and tooth profiles", Mechanism and Machine Theory, Volume 43, Issue 9, pp. 1158-1174, September 2008.

[16] Germano Del Pio, Ettore Pennestrì, Pier Paolo Valentini, "Kinematic and power-flow analysis of bevel gears planetary gear trains with gyroscopic complexity", Mechanism and Machine Theory, Volume 70, pp. 523-537, December 2013.

[17] Aref Bahrami Ghahnavieh, Saleh Akbarzadeh, Peiman Mosaddegh, "A numerical study on the performance of straight bevel gears operating under mixed lubrication regime", Mechanism and Machine Theory, Volume 75, pp. 27-40, May 2014.

[18] Alfonso Fuentes, Faydor L. Litvin, Baxter R. Mullins Ron Woods, Robert F. Handschuh, "Design and Stress Analysis of Low-Noise Adjusted Bearing Contact Spiral Bevel Gears”, Journal of Mechanical Design, Vol. 124, pp.525-532, September 2002. 